\title{
Sandpaper and Topical 5-Fluorouracil: A Different Therapeutic Modality for Acral Vitiligo
}

\author{
Eman Asker', Ghada F. Mohammed ${ }^{2 *}$, Amal H. A. Gomaa' ${ }^{2}$, Moustafa M. K. Eyada ${ }^{2}$ \\ ${ }^{1}$ Department of Dermatology and Venereology, Ministry of Health, Egypt \\ ${ }^{2}$ Department of Dermatology and Venereology, Faculty of Medicine, Suez Canal University, Ismailia, Egypt \\ *Corresponding Author: Ghada F. Mohammed, Department of Dermatology and Venereology, Faculty \\ of Medicine, Suez Canal University, Ismailia,Egypt,Email:Dr_Ghada77@hotmail.com
}

\begin{abstract}
Background: Acral vitiligo (AV) is resistant to treatment.

Aim: To evaluate efficacy and safety of combining sandpaper (SP) and 5Fluorouracil (5FU) in treating AV.

Methods: This study included 45 adult patients with AV. After assigning in 3 groups randomly; treatment was delivered for group I by 5FU, SP for group II and SP followed by 5FU for group III for a maximum period of 5 months. The lesions were then evaluated both qualitatively and quantitatively.

Results: Most (60\%) of the lesions in group III achieved G0, and 40\% of lesions achieved G1 repigmentation. This response was non-significantly different between the three groups. This not achieved in periangual areas in hands and feet. Pain was tolerable during sessions or at sites of 5FU application. Transient hyperpigmentation, itching and infection were temporary side effects; however, Koebnerization was not detected.
\end{abstract}

Conclusion: In spite of the tolerability and safety of sandpaper technique with 5-Fluorouracil, the results was not promising.

Keywords: Acral vitiligo, sand paper, 5Fluorouracil.

\section{INTRODUCTION}

Acral vitiligo (AV) is resistant to treatment $[1$, 2]. There are many factors help in developing this resistance. Low density of pilosebaceous follicles, melanocyte, melanocyte stem cell reservoirs, baseline epidermal stem cell factor from which the melanocytes could migrate, lower stem cell factor (SCF), c-kit, MHCII expression as well as lower density of Langerhans cells (LC), and high rate of koebnerization are playing roles in resistance of acral lesions [1,3,4]

\section{OBJECTIVE}

This is a single blind, comparative, randomized controlled study to highlight the efficacy and safety of sandpaper (SP) and 5Fluorouracil (5FU) in treating AV.

\section{METHODS}

\subsection{Study Design and Patient Population}

This prospective, pilot, parallel group and randomized controlled trial conducted over 12 months. It received an approval from the Institutional Research Review Board Ethical
Committee of the Suez Canal University, Faculty of Medicine, Ismailia, Egypt. It conducted in accordance with the guidelines of the Helsinki Declaration and performed after obtaining the informed consent from all participants.

Inclusion criteria for this study included AV with no evidence of any systemic or dermatologic disease. Exclusion criteria included pregnant women, lactating women, and patients who were receiving treatment for AV or oral retinoid within 6 months. Forty-nine patients were eligible for participation, and 46 completed the study. Complete medical history obtained from each patient, and underwent a general physical examination. They assigned randomly to one of three groups described below.

\subsubsection{Group I (5FU)}

Sixteen patients applied 5FU once daily to the lesions for 7 days per month for 5 consecutive months. 


\subsubsection{Group II (Sandpaper)}

With sterilized sandpaper, the skin of the recipient area in 17 patients manually abraded by hand until the pinpoint bleeding became evident. By using another piece of sandpaper, the skin of the donor area also manually abraded by hand until the pinpoint bleeding became evident. The sandpaper with the epidermal fragments then applied to only one of the previously treated areas with topical 5FU. A waterproof dressing applied ensuring that the sandpaper stayed firmly attached to the recipient site (32). The donor area cleansed with saline and covered with paraffin gauze, leaving it to heal by secondary intention. Dressings from the recipient and donor areas left in place for 1 week before removing. From the day after the bandages removed, patients received 5 minutes of direct sunlight daily per week until study completion (5 months).

\subsubsection{Group III (sandpaper and 5FU)}

Sixteen patients started the application of topical (5FU) on the receptor area once daily for 7 days under occlusion; erythema and erosions noticed by the end of the week. Then, the same sandpaper technique as group II applied to all of them.

\subsection{Assessment Methods}

Three methods used to assess the results: An Investigator's global assessment (IGA), Subjective evaluation of tolerance (pain), and vitiligo disease activity score (VIDA score. At each monthly visit, digital photographs taken of the tested area at standardized distance and lighting conditions.

\subsubsection{Assessment of Effectiveness of the Treatment by}

Three professional independent observers at the institution examined the clinical photographs obtained at study initiation and month 5; using a Sony digital camera (8.2 mega pixels). An Investigator's global assessment (IGA) enrolled five grades of repigmentation and expressed qualitively [G0, none; G1, < 25\% (poor); G2, 25-49\% (fair); G3, 50-74\% (good), G4, $\geq 75 \%$ (excellent)]. The criterion of success (desirable response) chosen was a repigmentation of at least $50 \%$ (IGA 3 or 4) [5]. Quantitative evaluation of the response also performed in a numerical percentage for precise statistical evaluation [6].

\subsubsection{Assessment of the Safety of the Treatment} by

Subjective evaluation of tolerance (pain) by a 5 point scale (1=none, $2=$ slight, $3=$ =moderate, $4=$ severe, $5=$ =intolerable) and satisfaction of the patients was made on a 5 point scale $(1=$ not satisfied, $2=$ =slightly satisfied, $3=$ =satisfied, $4=$ very satisfied, $5=$ extremely satisfied) and his wiliness to repeat the procedure. In addition, subjective assessment of possible side effects during the follow-up visits and at end of the study applied.

\subsubsection{Assessment of the Disease Activity by}

The disease activity was scored by means of the "vitiligo disease activity score (VIDA score)" before and after 5 months of treatment. The Vitiligo Disease Activity (VIDA) Score isa 6 point scale for assessing vitiligo activity based on individuals own opinion of the present disease activity regarding expansion of existing lesions or appearance of new lesions gauged during a period ranging from less than 6 weeks to one year table [7]. It is suggested that surgery for vitiligo may be performed only in patients with VIDA scores of -1 or 0 .

\subsection{Statistical Analysis}

All statistical analysis was performed using SPSS software, version 16 (SPSS, Inc, an IBM Company, Chicago, Illinois). Statistical significance in a two-sided test was defined as $\mathrm{P}$ $<0.05$.

\section{RESUlts}

\subsection{Demographic Findings}

Forty-five patients with AV completed the entire study. Four patients were lost to followup. The mean age of study completers in group I, II and III was $(34.2 \pm 11.8,34.12 \pm 2.19$ and $35.9 \pm 2.33$, respectively). The prevailing skin phototype in all groups was type III. It represented $81.8 \%, 68.9 \%$, and $69.7 \%$ of the patients in group I, II and III, respectively. Family history of vitiligo was not significantly different between the three groups. All the patients were resistant to the previously received treatment [topical and systemic steroids, phototherapy and photo chemotherapy]. The mean age of onset of lesions was $(29.9 \pm 0.3$, $31.9 \pm 1.7$ and $32.2 \pm 0.5$ years) in group I, II, and III, respectively. The mean duration of the disease was $(5.0 \pm 3.5,6.8 \pm 0.8$ and $7.4 \pm$ 5.5years) in group I, II, and III, respectively. Inflammation and re-epithelization time among patients was $7.9 \pm 5.8$ and ranged between 10 18 days. 
There was non-significant difference in the overall qualitative response to treatment between the three groups. This expressed by rate of repigmentation [G0 and G1] between the three groups [Table (1)].

The lesions with vitilgo were assessed by this study that assumed repigmentation and were assigned them in grades G1, G2, G3 and G4. Results with G1 were statistically nonsignificant in the dorsum of hands and feet

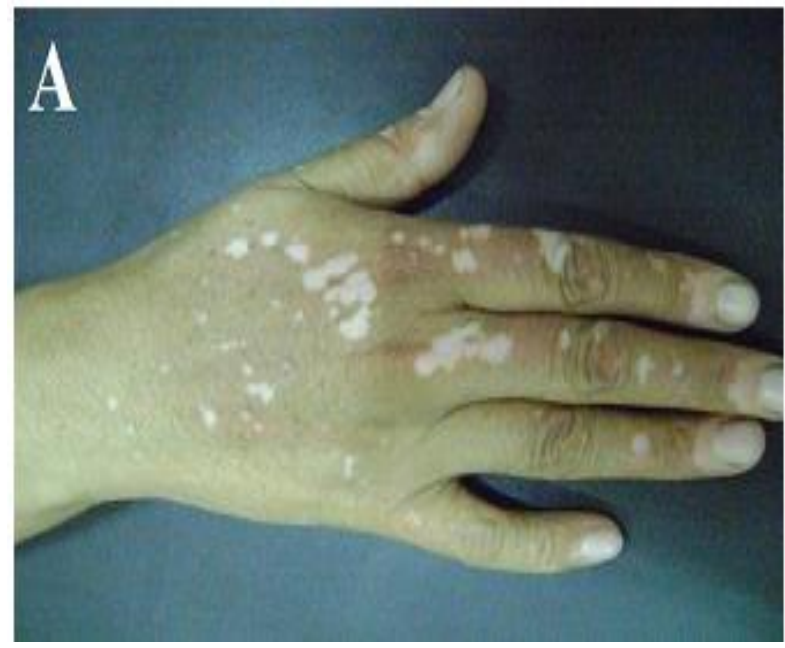

during the course of treatment. Regarding the fingers and toes response the difference between the three groups was statistically on-significant. The periungal area didn't show any repigmnetation and the difference was statistically non-significant [Tables (2-6)].

Only one patient in group II and III had infection and were treated with proper antibiotics.

Figure1: $G 0$ response is observed in both lesions on the dorsum of the hand, before (A) and after treatment (B)

Table1: Overall Qualitative Response to Treatment

\begin{tabular}{|l|l|l|l|l|l|l|}
\hline \multirow{2}{*}{ Grades of improvement } & \multicolumn{2}{|c|}{ Group I } & \multicolumn{2}{c|}{ Group II } & \multicolumn{2}{c|}{ Group III } \\
\cline { 2 - 7 } & No. & \% & No & \% & No & \% \\
\hline G0 (0\%) & 13 & $86.7 \%$ & 10 & $66.7 \%$ & 9 & $60 \%$ \\
G1 (<25\%) or poor & 2 & $13.3 \%$ & 5 & $33.3 \%$ & 6 & $40 \%$ \\
G2 (25- 49\%) or fair & 0 & 0 & 0 & $0 \%$ & 0 & $0 \%$ \\
G3 (50-74\%) or good & 0 & 0 & 0 & $0 \%$ & 0 & $0 \%$ \\
G4 ( $\geq$ 75) or excellent & 0 & 0 & 0 & $0 \%$ & 0 & $0 \%$ \\
\hline
\end{tabular}

No. $=$ Number

Table2: Grades of Improvement

\begin{tabular}{|c|c|c|c|c|c|}
\hline & Group I & Group II & Group III & t- test & p-value \\
\hline Grades of & Mean \pm SD & Mean \pm SD & Mean \pm SD & 0.377 & 0.72 \\
improvement & $\mathbf{0 . 3} \pm \mathbf{0 . 4 7}$ & $\mathbf{0 . 3 3} \pm \mathbf{0 . 4 8}$ & $\mathbf{0 . 4} \pm \mathbf{0 . 5}$ & & \\
\hline
\end{tabular}

Table3: Comparison of the Therapeutic Efficacy of the Three Treatment Groups Monthly During Follow up after Session

\begin{tabular}{|l|l|l|l|l|l|l|l|l|l|l|}
\hline Grading & \multicolumn{2}{|c|}{$\mathbf{1}^{\text {st }} \mathbf{m}$} & \multicolumn{2}{c|}{$\mathbf{2}^{\text {nd }} \mathbf{m}$} & \multicolumn{2}{c|}{$\mathbf{3}^{\text {rd }} \mathbf{m}$} & \multicolumn{2}{c|}{$\mathbf{4}^{\text {th }} \mathbf{m}$} & \multicolumn{2}{c|}{$5^{\text {th }} \mathbf{m}$} \\
\hline Group I & No. & $\%$ & No. & $\%$ & No. & $\%$ & No. & $\%$ & No. & $\%$ \\
\hline 0 & 15 & 100 & 15 & 100 & 15 & 100 & 14 & 93.3 & 13 & 86.6 \\
1 & 0 & 0 & 0 & 0 & 0 & 0 & 1 & 6.66 & 2 & 13.3 \\
2 & 0 & 0 & 0 & 0 & 0 & 0 & 0 & 0 & 0 & 0 \\
3 & 0 & 0 & 0 & 0 & 0 & 0 & 0 & 0 & 0 & 0 \\
4 & 0 & 0 & 0 & 0 & 0 & 0 & 0 & 0 & 0 & 0 \\
5 & 0 & 0 & 0 & 0 & 0 & 0 & 0 & 0 & 0 & 0 \\
\hline Group II & No. & $\%$ & No. & $\%$ & No. & $\%$ & No. & $\%$ & No. & $\%$ \\
\hline 1 & 10 & 66.6 & 10 & 66.6 & 10 & 66.6 & 10 & 66.6 & 10 & 66.6 \\
2 & 5 & 33.3 & 5 & 33.3 & 5 & 33.3 & 5 & 33.3 & 5 & 33.3 \\
3 & 0 & 0 & 0 & 0 & 0 & 0 & 0 & 0 & 0 & 0 \\
4 & 0 & 0 & 0 & 0 & 0 & 0 & 0 & 0 & 0 & 0 \\
5 & 0 & 0 & 0 & 0 & 0 & 0 & 0 & 0 & 0 & 0 \\
\hline
\end{tabular}


Sandpaper and Topical 5-Fluorouracil: A Different Therapeutic Modality for Acral Vitiligo

\begin{tabular}{|l|l|l|l|l|l|l|l|l|l|l|}
\hline Group III & No. & $\%$ & No. & $\%$ & No. & $\%$ & No. & $\%$ & No. & $\%$ \\
\hline 0 & 9 & 60 & 9 & 60 & 9 & 60 & 9 & 60 & 9 & 60 \\
1 & 6 & 40 & 6 & 40 & 6 & 40 & 6 & 40 & 6 & 40 \\
2 & 0 & 0 & 0 & 0 & 0 & 0 & 0 & 0 & 0 & 0 \\
3 & 0 & 0 & 0 & 0 & 0 & 0 & 0 & 0 & 0 & 0 \\
4 & 0 & 0 & 0 & 0 & 0 & 0 & 0 & 0 & 0 & 0 \\
5 & 0 & 0 & 0 & 0 & 0 & 0 & 0 & 0 & 0 & 0 \\
\hline
\end{tabular}

$m=$ month

No. $=$ Number

Table4: The Relationship between Improvement and Site of Lesion in Group I Treated with Sandpaper Technique Alone

\begin{tabular}{|l|l|l|l|l|l|l|l|l|l|l|l|l|l|}
\hline & \multicolumn{2}{|c|}{$\mathbf{1}^{\text {st }} \mathbf{m}$} & \multicolumn{2}{c|}{$\mathbf{2}^{\text {nd }} \mathbf{m}$} & \multicolumn{2}{c|}{$\mathbf{3}^{\text {rd }} \mathbf{m}$} & \multicolumn{2}{c|}{$\mathbf{4}^{\text {th }} \mathbf{m}$} & \multicolumn{2}{|c|}{$\mathbf{5}^{\text {th }} \mathbf{m}$} & \multicolumn{1}{|c|}{ Fisher exact test } & P-value \\
\hline Hand & No. & $\%$ & No. & $\%$ & No. & $\%$ & No. & $\%$ & No. & $\%$ & & \\
\cline { 2 - 12 } Periangual & 5 & 100 & 0 & 0 & 0 & 0 & 0 & 0 & 0 & 0 & 9.2 & $<.01$ \\
Fingers & 7 & 100 & 1 & 16.6 & 0 & 0 & 0 & 0 & 0 & 0 & & \\
Dorsum & 2 & 100 & 0 & 0 & 0 & 0 & 0 & 0 & 0 & 0 & & \\
Wrist & 0 & 0 & 0 & 0 & 0 & 0 & 0 & 0 & 0 & 0 & & NS \\
\hline Foot & & & & & & & & & & & & \\
Periangual & 3 & 100 & 0 & 0 & 0 & 0 & 0 & 0 & 0 & 0 & 0.4 & \\
Toes & 2 & 100 & 0 & 0 & 0 & 0 & 0 & 0 & 0 & 0 & & \\
Dorsum & 4 & 57.1 & 3 & 42.9 & 0 & 0 & 0 & 0 & 0 & 0 & & \\
Ankle & 0 & 0 & 2 & 100 & 0 & 0 & 0 & 0 & 0 & 0 & & \\
\hline
\end{tabular}

$m=$ month

No. $=$ Number

NS = Non significant

Table5: The Relationship between Improvement and Site of Lesion in Group II Treated with Sandpaper Technique Alone

\begin{tabular}{|l|l|l|l|l|l|l|l|l|l|l|l|l|l|l|}
\hline & \multicolumn{2}{|c|}{$\mathbf{1}^{\text {st }} \mathbf{m}$} & \multicolumn{2}{c|}{$\mathbf{2}^{\text {nd }} \mathbf{m}$} & \multicolumn{2}{c|}{$\mathbf{3}^{\text {rd }} \mathbf{m}$} & \multicolumn{2}{c|}{$\mathbf{4}^{\text {th }} \mathbf{m}$} & \multicolumn{2}{|c|}{$\mathbf{5}^{\text {th }} \mathbf{m}$} & Fisher exact test & P-value \\
\hline Hand & No. & $\%$ & No. & \% & No. & \% & No. & \% & No. & \% & & \\
Periangual & 5 & 100 & 0 & 0 & 0 & 0 & 0 & 0 & 0 & 0 & 9.2 & & $<.01$ \\
Fingers & 5 & 83.3 & 1 & 16.6 & 0 & 0 & 0 & 0 & 0 & 0 & & \\
Dorsum & 3 & 100 & 0 & 0 & 0 & 0 & 0 & 0 & 0 & 0 & & \\
Wrist & 0 & 0 & 2 & 100 & 0 & 0 & 0 & 0 & 0 & 0 & & NS \\
\hline Foot & & & & & & & & & & & & \\
Periangual & 2 & 66.6 & 1 & 33.3 & 0 & 0 & 0 & 0 & 0 & 0 & 0.4 & \\
Toes & 1 & 50 & 1 & 50 & 0 & 0 & 0 & 0 & 0 & 0 & & \\
Dorsum & 4 & 57.1 & 3 & 42.5 & 0 & 0 & 0 & 0 & 0 & 0 & & \\
Ankle & 0 & 0 & 1 & 100 & 0 & 0 & 0 & 0 & 0 & 0 & & \\
\hline
\end{tabular}

$m=$ month, No. $=$ Number

NS = Non significant

Table6: The Relationship between Grades of Improvement and Site of Lesion in Group III Treated with Sandpaper Technique Combined with Topical 5 Flurouracil Cream

\begin{tabular}{|c|c|c|c|c|c|c|c|c|c|c|c|c|}
\hline & \multicolumn{2}{|c|}{$\mathbf{1}^{\mathrm{st}} \mathrm{m}$} & \multicolumn{2}{|c|}{$2^{\text {nd }} \mathrm{m}$} & \multicolumn{2}{|c|}{$3^{\text {rd }} \mathbf{m}$} & \multicolumn{2}{|c|}{$4^{\text {th }} \mathrm{m}$} & \multicolumn{2}{|c|}{$5^{\text {th }} \mathrm{m}$} & \multirow[t]{2}{*}{ Fisher exact test } & \multirow[t]{2}{*}{ P-value } \\
\hline Hand & No. & $\%$ & No. & $\%$ & No. & $\%$ & No. & $\%$ & No. & $\%$ & & \\
\hline Periangual & 3 & 42.8 & 4 & 57.1 & 0 & 0 & 0 & 0 & 0 & 0 & 0.05 & NS \\
\hline Finger & 4 & 40 & 6 & 60 & 0 & 0 & 0 & 0 & 0 & 0 & & \\
\hline Dorsum & 5 & 80 & 5 & 50 & 0 & 0 & 0 & 0 & 0 & 0 & & \\
\hline Wrist & 5 & 50 & 5 & 50 & 0 & 0 & 0 & 0 & 0 & 0 & & \\
\hline Foot & & & & & & & & & & & 7.7 & NS \\
\hline$\overline{\text { Periangual }}$ & 1 & 100 & 0 & 0 & 0 & 0 & 0 & 0 & 0 & 0 & & \\
\hline Toes & 1 & 100 & 0 & 0 & 0 & 0 & 0 & 0 & 0 & 0 & & \\
\hline Dorsum & 2 & 100 & 0 & 0 & 0 & 0 & 0 & 0 & 0 & 0 & & \\
\hline Ankle & 3 & 100 & 0 & 0 & 0 & 0 & 0 & 0 & 0 & 0 & & \\
\hline
\end{tabular}

$m=$ month, No. $=$ Number

NS = Non significant 


\subsection{Assessment of Disease Stability}

All the patients reported zero VIDA score before and after the end of treatment, which indicates that the disease was stable. There was no progression of old lesions and/ or development of new lesions and absence of Koebner phenomenon in the previous one year and after 6 months of treatment.

\subsection{Assessment of Safety of Treatment}

All patients in group II and III reported none $(59.1 \%)$ to slight $(22.4 \%)$ pain during the session.

\section{DisCUSSION}

Combining topical medical management with surgical strategies is being increasingly studied in managing resistant vitiligo patches [8]. Dermabrasion together with topical 5FU application was previously used in treating vitiligo with good results [9-13]. However, this combination was ineffective in treating segmental vitiligo [14].

Thus, combination of 5FU with other treatment modalities can improve vitiligo lesions, decrease treatment duration, and increase patients' compliance. So, this study was designed to compare the efficacy and safety of combination treatment with sandpaper plus 5FU cream in treating resistant acral vitiligo. We hypothesize that it is possible to obtain and transfer melanocytes and keratinocytes using the sandpaper method.

This study showed that mean duration of inflammation and re-epithelization among group III was $7.9 \pm 5.8$ (range $10-18$ ) days. In this study, the overall qualitative response to treatment showed non-significant difference with using the combination treatment group. These results did not agree with other previous studies [15, 16]; however, those high responses were achieved in non acral vitiligo. On using dermabrasion plus 5FU cream in treating vitiligo, the overall response was $66.7 \%$ (6) of participants and $78.1 \%$ of lesions, respectively showing moderate to marked response (50 $>75 \%)[6,16]$.

On comparing the therapeutic efficacy of the three treatment groups monthly after every session for 5 months according to their distribution on the hands and feet was nonsignificantly different among patients in the three groups $(\mathrm{P}>0.05)$. As regard the lesions in the toes and periungal area of fingers and toes along the 5 months of treatment, there was statistically non-significant difference between the three groups. Concerning lesions in the periungal area of fingers and toes, the response was poor.

Failure of pigmentation may due to un-survival of melanocytes. This may either to: lower baseline epidermal stem cell factor, lower stem cell factor (SCF), c-kit, MHCII expression as well as lower density of Langerhans cells (LC), [1, 3, 4]

Side effects to applied treatment in all groups showed that patients in group II and III experienced more frequent side-effects as compared with those in group I. However, this difference was statistically non-significant except for transient hyperpigmentation. These side effects were transient and disappeared after discontinuation of treatment.

Slight to moderate pain was encountered in all patients treated with sandpaper plus topical 5fluorouracil cream during the superficial ablation process by sandpaper but it was tolerated. Infection was detected in 1 patients in group II as he did not follow instructions after procedure. They improved with the appropriate systemic and topical antibiotics then they continue their sessions after complete recovery of infection. Itching occurred in 2 patients in group III after application of 5\% 5-FU cream. This was a common local adverse effect of topical 5FU. They took oral antihistamine during application of 5FU cream and itching was relieved. It was transient and disappears after discontinuation of 5FU application.

Transient hyperpigmentation was detected in all (100\%) patients of group II and III. Patients accepted this hyperpigmentation. The areas of skin showed hyperpigmentation return to normal skin color within few weeks to months. These result agreed with other studies [15-18]. Hypertrophic scarring was not reported because of superficial ablation process, removing of epidermis, avoiding of dermis and application of 5 -fu cream once daily to achieve moderate inflammation not deep erosion [15, 19].

\section{CONClusion}

In spite of the tolerability and safety of sandpaper technique with 5-Fluorouracil, the results was not promising.

\section{REFERENCES}

[1] Mutalik S.Surgical management of acral vitiligo. In Somesh G, Mats O,Amrinder K, Jean-Paul O, eds. Surgical Management of Vitiligo, Blackwell publishing Ltd, Oxford, UK; 2007, 225-228. 
[2] Falabella R. Surgical approaches for stable vitiligo. Dermatol Surg; 2005, 31: 1277-1284.

[3] Roelandts R. Photochemotherapy for vitiligo. Photodermatology, Photoimmunology and Photomedicine Journal; 2003, 19: 1-4.

[4] Esmat S.M., El-Tawdy A.M., Hafez G.A., Zeid O.A., Abdel Halim D.M., Saleh M.A., Leheta T.M. and ElMofty M. Acral lesions of vitiligo: why are they resistant to photochemotherapy? JEADV, 2012, 26, 1097-1104.

[5] Bayoumi W., Fontas E., Sillard L., Duff F.L., Ortonne J.P., Bahadoran P., Lacour J.P. and Passeron P. Effect of a preceding laser dermabrasion on the outcome of combined therapy with narrowband ultraviolet $\mathrm{B}$ and potent topical steroids for treating nonsegmental vitiligo in resistant localizations. Br J Dermatol; 2011, 166: 208-211.

[6] Anbar T.S., Westerhof W., Abdel-Rahman A.T., Ewis A.A. and El- Khayyat M.A. Effect of one session of ER: YAG laser ablation plus topical 5Fluorouracil on the outcome of shortterm NBUVB phototherapy in the treatment of non-segmental vitiligo: a left-right comparative study. Photodermatol Photoimmunol Photomed; 2008, 24(6): 322-9.

[7] Njoo M.D., Bossuyt P.M.M., Westerhof W. Management of vitiligo: result of questionnaire among dermatologist in the Netherlands. Int J Dermatol.; 1999, 38: 866-872.

[8] Taieb A. and Gauthier Y. Combining medical and surgical therapies. In: Gupta S, Olsson MJ, Kanwar AJ, Ortonne JP, editors. Surgical management of vitiligo, Oxford: Blackwell Publishing; 1st ed. 2007, 56-62.

[9] Tsuji T. and Hamada T. Topically administered 5- fluorouracil in vitiligo. Arch Dermatol. 1983, 119: $722-27$.

[10] Szekeres E. and Morvay M. Repigmentation of vitiligo macules treated topically efudix cream. Dermatologica; 1985, 171: 55 - 59.
[11] Ghozz M.M. Vitiligo treatment by topical application of 5- fluorouracil cream following dermabrasion. Egypt. J Derm and Vener, 1996, 5: 135-139.

[12] Esfandiarpour I., Nikiyan Y. and Farajzadeh S. The effect of topical 5- fluorouracil ointment along with epidermal abrasion in treatment of vitiligo. J Kerman Univ Med Sci; 1998, 5:1106.

[13] Sethi S., Mahajan B.B., Gupta R.R. and Ohri A. Comparative evaluation of the therapeutic efficacy of dermabrasion, dermabrasion combined with topical 5\% 5-fluorouracil cream, and dermabrasion combined with topical placentrex gel in localized stable vitiligo. Int J Dermatol.; 2007, 46(8):875-79.

[14] Mohammad N.S., Elgoweini M.F. and Khad N.A. Dermatomal vitiligo therapeutic implication of dermabrasion. Journal of Pan 2; 2008, 19(1): 21-29.

[15] Quezada N, Machado Filho CA, De La Sotta P, Uribe P.Melanocytes and keratinocytes transfer using sandpaper technique combined with dermabrasion for stable vitiligo. Dermatol Surg. 2011 Feb; 37(2):192-8.

[16] Garg T., Chander R. and Jain A. Combination of Microdermabrasion and 5-Fluorouracil to Induce Repigmentation in Vitiligo: An Observational Study. Dermatol Surg; 2011, 37:1763-1766.

[17] Hrushesky W.J. Serpentine supravenous fluorouracil hyperpigmentation. JAMA 1976; 236(2): 138.

[18] Bernstein L.J., Kauvar A.N.B. and Grossman M.C. The short- and long-term side effects of carbon dioxide laser resurfacing. Dermatol. Surg.; 1997, 23:519-25.

[19] Chen Y.F., Yang P.Y., Hu D.N., Kuo FS, Hung CS, Hung CM. Treatment of vitiligo by transplantation of cultured pure melanocyte suspension: analysis of 120 cases. J Am Acad Dermatol 2004; 51: 68-74.

Citation: Eman Asker, Ghada F. Mohammed, Amal H. A. Gomaa, Moustafa M. K. Eyada, Sandpaper and Topical 5-Fluorouracil: A Different Therapeutic Modality for Acral Vitiligo. ARC Journal of Dermatology. 2019; 4(1):1-6. doi:dx.doi.org/10.20431/2456-0022.0401001.

Copyright: (C) 2019 Authors. This is an open-access article distributed under the terms of the Creative Commons Attribution License, which permits unrestricted use, distribution, and reproduction in any medium, provided the original author and source are credited. 